Brazilian Journal

of Chemical

ISSN 0104-6632

Engineering

\title{
OPTIMIZATION OF SOLID-STATE FERMENTATION FOR BIOHERBICIDE PRODUCTION BY Phoma sp.
}

\author{
R. Klaic ${ }^{1}$, D. Sallet ${ }^{1}$, E. L. Foletto ${ }^{1}$, R. J. S. Jacques ${ }^{2}$, \\ J. V. C. Guedes ${ }^{3}$, R. C. Kuhn ${ }^{1 *}$ and M. A. Mazutti ${ }^{1}$ \\ ${ }^{1}$ Department of Chemical Engineering, Federal University of Santa Maria, \\ Av. Roraima, 1000, Santa Maria, RS, 97105-900, Brazil. \\ Phone: +55 5532208691 \\ E-mail: raquelckuhn@yahoo.com.br \\ ${ }^{2}$ Department of Soil Science, Federal University of Santa Maria, \\ Av. Roraima, 1000, Santa Maria, RS, 97105-900, Brazil. \\ ${ }^{3}$ Department of Plant Protection, Federal University of Santa Maria, \\ Av. Roraima, 1000, Santa Maria, RS, 97105-900, Brazil.
}

(Submitted: September 29, 2015; Revised: December 18, 2015; Accepted: January 21, 2016)

\begin{abstract}
In this work the bioherbicide production from Phoma sp. by solid-state fermentation was optimized. Agroindustrial residues such as bagasse, soybean bran and corn steep liquor were used as substrate. The bioherbicide was extracted from the fermented solid and the supernatant was applied for the control of the target plant. The evaluated responses in the bioassay were plant height, root length, fresh and dry weight, number of flowers and phytotoxicity. The results in the bioassays demonstrated that the bioherbicide presented activity towards the target plant and the intensity of the effect was influenced by the formulation of the fermentation medium. The optimized condition for bioherbicide production was (wt \%): moisture content 70.0, soybean bran content 30.0 and corn steep liquor (CSL) 20.0, it being possible to obtain an injury phytotoxicity level of 40 . The bioherbicide showed a mode of action based on the inhibition of carotenoid biosynthesis.
\end{abstract}

Keywords: Bioherbicide; Bioassay; solid-state fermentation; Phoma sp.

\section{INTRODUCTION}

Weeds are one of the major contributing factors to yield loss in agricultural production worldwide (Boyetchoko et al., 2002; Charidattan and Dinoor 2000), because they compete with crop plants for light, water, nutrients, heat energy, carbon dioxide, and space (Boyetchoko et al., 2002; Barton, 2004; Penariol et al., 2008). Reductions may also be caused by the production of growth-inhibiting compounds due to allelopathy (Rosskopf et al., 1999).

While weeds contribute significantly to crop yield losses, some of the reported negative impacts of agrochemicals such as residues in soil and water, spray drift, and weed species exhibiting herbicide resistance underscore the importance of exploring alternatives to chemical herbicides (Boyetchoko et al., 2002). The alternative that has been used is biological control, where a microorganism or a secondary metabolite produced by it is employed as control agent in a narrow field of application (Zhou et al., 2004; Green, 2014). However, there are few molecules produced industrially and commercialized. By the year 2010 there were only 11 commercially successful bioherbicides (Ash, 2010), this shows that there is a great market to be explored.

Many microorganisms can be used for bioherbicide production, including fungi from the genera Phoma sp. (Klaic et al., 2013; Klaic et al. 2015; Copping, and Duke, 2007) Some studies report the use of fungi from Phoma $\mathrm{sp}$. as bioherbicides using submerged fermentation. Bailey

*To whom correspondence should be addressed 
et al. (2011) evaluated the action of Phoma macrostoma as bioherbicide, whereas Zhang et al. (2012) used Phoma sp. to obtain antimicrobial extracts. Parra et al. (2005) optimized the production of secondary metabolites of Phoma sp. with herbicide activity.

A barrier for bioherbicide production is the development of an economically viable process (Mitchell, 2003). The production of a bioactive molecule is strictly related to the formulation of the medium and the type of fermentation. Solid state fermentation has been shown to be promising in the development of several bioprocesses/products and offers an alternative fermentation method that possesses several biotechnological advantages over the conventional submerged fermentation (Pandey, 2003; Singhania et al., 2010). The substrates are often agroindustrial residues such as sugarcane bagasse, rice husk, wheat bran and soybean meal. In many cases, after fermentation the substrates are ground and applied in granular formulations of bioherbicides. Some researchers used extract obtained from fermented grains as bioherbicide (Hoagland et al., 2007).

Based on these aspects, the main objective of this work was to optimize the media composition for bioherbicide production from Phoma sp. by solid-state fermentation. Agroindustrial residues such as bagasse, soybean and corn steep liquor were employed as substrate. After the fermentation, the bioherbicide was extracted from the fermented solid and applied for the control of the target plant. The responses evaluated in the bioassay were the plant height, root length, fresh and dry weight, number of flowers and phytotoxicity.

\section{MATERIALS AND METHODS}

\section{Materials}

Sugarcane bagasse was obtained in a microdistillery located at the Federal University of Santa Maria. The sample was dried, milled and sieved. The mean particle size of the bagasse used was $1.32 \mathrm{~mm}$. The soybean bran was purchased in a local market and the mean particle size was $0.95 \mathrm{~mm}$. Corn steep liquor (CSL) was obtained from Ingredion (Mogi Guaçu, SP, Brazil) and was used as received.

\section{Microorganism, inoculum and fermentations}

The strain of Phoma sp. NRRL Y-7571 was obtained from the National Center for Agricultural Utilization Research - EUA (ARS). The culture was maintained in potato dextrose agar (PDA) at $4-6^{\circ} \mathrm{C}$ and subcultured every 15 days. Cell production for pre-inoculum was from the incubation of fungi in a Petri dish containing PDA media for 8 days at $28^{\circ} \mathrm{C}$. Afterwards, the Petri dish was washed with $5 \mathrm{~mL}$ of sterilized water and transferred to the fermentation medium.

The inoculum was cultivated in Erlenmeyers of 250 $\mathrm{mL}$ containing $50 \mathrm{~mL}$ of fermentation medium at $28^{\circ} \mathrm{C}$, $120 \mathrm{rpm}$ for 5 days in an orbital shaker (INNOVA 44R, New Brunswick Scientific). The composition was (g.L $\left.{ }^{-1}\right)$ : glucose 20.0, peptone 10.0, yeast extract 7.5, $\left(\mathrm{NH}_{4}\right)_{2} \mathrm{SO}_{4}$ 2.0, $\mathrm{FeSO}_{4} \cdot 7 \mathrm{H}_{2} \mathrm{O} 1.0, \mathrm{MnSO}_{4} \cdot \mathrm{H}_{2} \mathrm{O} 1.0$ and $\mathrm{MgSO}_{4} 0.5$ (Parra et al., 2005).

\section{Optimization of the fermentation medium}

Fermentations were carried out in conical flasks (500 $\mathrm{mL}$ ) containing $10 \mathrm{~g}$ of solid substrate at $28^{\circ} \mathrm{C}$ for 5 days in a chamber with temperature and humidity control (POLEKO, model KK 350). Afterwards, the solid substrate was supplemented and the moisture content adjusted to the specified level. Each flask was covered with hydrophobic cotton and autoclaved at $121^{\circ} \mathrm{C}$ for $20 \mathrm{~min}$. Preliminary studies showed that no changes in moisture content of the substrate after autoclaving were detected. After cooling, each flask was inoculated using $10 \mathrm{~mL}$ of inoculum.

The fermentation medium consisted of sugarcane bagasse (main substrate used as support and carbon source) supplemented with soybean bran, corn steep liquor (CSL) and initial moisture content. A Central Composite Rotatable Design (CCRD) with 14 runs plus 3 central points was conceived to determine the effects of independent variables on the production of phytotoxins with herbicidal action. The range of variables investigated was $(\mathrm{wt} \%)$ : soybean bran 8-32, CSL 8-32 and moisture content 50-80. The response evaluated in the experimental design was the level of injury caused by the fermented extract on the target plant.

\section{Extraction of bioactive compounds}

After fermentation, the bioactive compounds of each assay were extracted using $100 \mathrm{~mL}$ of distilled water in an orbital shaker at $100 \mathrm{rpm}$ and $28^{\circ} \mathrm{C}$ during $1 \mathrm{~h}$ (INNOVA 44, New Brunswick Scientific). The broth obtained from the extraction was filtered and stored to be further applied in the bioassays.

\section{Bioassay to evaluate bioherbicide activity}

The herbicidal activity of fermented extract was determined using cucumber (Cucumis sativus L. variety wisconsin) as the target plant. Although it is not a weed, this species is sensitive to synthetic herbicides and is frequently used in bioassays; moreover, it presents fast and uniform seed germination and does not exhibit dormancy.

The bioassays were conducted in a greenhouse, where each experiment of the CCRD represented a treatment 
containing 20 plants. The application of the bioherbicide was carried out after 15 days of cucumber cultivation, when the plants presented 2 to 3 leaves. Approximately $30 \mathrm{~mL}$ of bioherbicide was applied in each treatment using a garden sprayer. Control assays were performed using the culture medium and others using only water. The plants were monitored during 21 days after application to verify the bioherbicidal action. The following aspects were evaluated for each treatment: plant height, root length, fresh weight, dry weight, number of flowers and phytotoxicity. To evaluate the phytotoxicity the scale of Frans and Crowley (1986), which is shown in Table 1, was used.

Table 1. Phytotoxic evaluation method in plants.

\begin{tabular}{ccc}
\hline$\%$ & Description of the Main Categories & Description Phytotoxicity of the Culture \\
\hline 0 & No Effects & No injury or reduction. \\
\hline 10 & Slight Effect & Slight discoloration or atrophy. \\
\hline 20 & & Some discoloration or atrophy. \\
\hline 30 & & Injury more pronounced, but not lasting. \\
\hline 40 & Moderate Effect & Moderate injury, usually with recovery. \\
\hline 50 & & More lasting injury, doubtful recovery. \\
\hline 60 & & Lasting injury without recovery. \\
\hline 70 & Severe Effect & Heavy injury, stand reduction. \\
\hline 90 & & Next crop destruction. \\
\hline 100 & & Rarely some plants remain. \\
\hline
\end{tabular}

Reference: Frans and Crowley (1986)

\section{Statistical Analysis}

The statistical analysis of the DCCR was carried out using the software Statistica ${ }^{\circledR} 8.0$ (Statsoft Inc., Tulsa, OK, USA), considering a significance level of $90 \%$. Tukey test was carried out using the software Assistat ${ }^{\circledR} 7.7$ (DEAGCTRN-UFCG, Campina Grande, PB, Brazil), considering a significance level of $95 \%$.

\section{RESULTS AND DISCUSSION}

Table 2 presents the results obtained in the 17 runs of the CCRD referring to the phytotoxicity of the bioherbicide towards the target plant. More severe phytotoxic effects were observed in runs $6,8,10,15,16$ and 17 . These treatments presented profound and discontinuous injury at a level ranging from 30-40. Runs 15, 16 and 17 (in triplicate at the central point of the CCRD) also presented significant injury in the target plant and showed good reproducibility of the results. Similar levels of phytotoxicity were obtained when water and fermentation media were used in the control experiments $(\sim 7)$. The Tukey test $(p<0.05)$ showed statistically significant differences in 13 runs of the CCRD in comparison with the controls.

Table 2. Matrix of the CCRD to evaluate the influence of independent variables on the bioherbicide production by solid-state fermentation.

\begin{tabular}{|c|c|c|c|c|}
\hline Run & $\begin{array}{c}\text { Moisture content } \\
(w \mathrm{t} \%)\end{array}$ & $\begin{array}{c}\text { CSL } \\
(w t \%)\end{array}$ & $\begin{array}{c}\text { Soybean bran } \\
(w t \%)\end{array}$ & $\begin{array}{c}\text { Phytotoxicity } \\
(\%)\end{array}$ \\
\hline 1 & $50(-1)$ & $8(-1)$ & (8) -1 & 26 \\
\hline 2 & $80(1)$ & $8(-1)$ & (8) -1 & 31 \\
\hline 3 & $50(-1)$ & $32(1)$ & (8) -1 & 12 \\
\hline 4 & $80(1)$ & $32(1)$ & (8) -1 & 15 \\
\hline 5 & $50(-1)$ & $8(-1)$ & (32) 1 & 25 \\
\hline 6 & $80(1)$ & $8(-1)$ & (32) 1 & 40 \\
\hline 7 & $50(-1)$ & $32(1)$ & (32) 1 & 25 \\
\hline 8 & $80(1)$ & $32(1)$ & (32) 1 & 36 \\
\hline 9 & $40(-1.68)$ & $20(0)$ & $20(0)$ & 15 \\
\hline 10 & $90(1.68)$ & $20(0)$ & $20(0)$ & 31 \\
\hline 11 & $65(0)$ & $0(-1.68)$ & $20(0)$ & 18 \\
\hline 12 & $65(0)$ & $40(1.68)$ & $20(0)$ & 38 \\
\hline 13 & $65(0)$ & $20(0)$ & $0(-1.68)$ & 13 \\
\hline 14 & $65(0)$ & $20(0)$ & $40(1.68)$ & 36 \\
\hline 15 & $65(0)$ & $20(0)$ & $20(0)$ & 39 \\
\hline 16 & $65(0)$ & $20(0)$ & $20(0)$ & 41 \\
\hline 17 & $65(0)$ & $20(0)$ & $20(0)$ & 40 \\
\hline
\end{tabular}

CSL: corn steep liquor 
The bioherbicidal activity of the fermented extracts was also investigated in terms of plant height, root length, fresh and dry weight and number of flowers, with the results presented in Table 3. The height of the plants for runs 1,2, $3,6,7$ and 9 presented statistically significant differences $(\mathrm{p}<0.05)$ in comparison with the controls. The lowest height $(8.27 \mathrm{~cm})$ was observed in run 9 and was about $3.2 \mathrm{~cm}$ lower than the control, whereas the greatest height $(11.46 \mathrm{~cm})$ was observed in run 14 . The mean height of the target in all runs was $10.33 \mathrm{~cm}$, with a variation coefficient of $13 \%$. The root system was also monitored and the results showed no statistical difference for fresh and dry weight of roots. These results indicate that the bioherbicide produced does not have an effect on the roots of plants. Concerning the aerial part of the plant, the dry weight of runs 6 and 7 was statistically significant, presenting a weight about $24 \%$ lower than the control; the fresh weight of run 6 was also statistically significant, presenting a weight about $20 \%$ lower than the control.

Table 3. Statistical analysis of the influence of the bioherbicide from Phoma sp. on different parts of the target plant

\begin{tabular}{|c|c|c|c|c|c|c|c|c|c|c|c|c|c|c|c|c|}
\hline \multirow{3}{*}{$\begin{array}{c}\text { Run } \\
\text { Witness }\end{array}$} & \multirow{2}{*}{\multicolumn{2}{|c|}{ Height Plant }} & \multirow{2}{*}{\multicolumn{2}{|c|}{$\begin{array}{l}\text { Length Root } \\
\text { Plant }\end{array}$}} & \multicolumn{4}{|c|}{ Fresh Weight } & \multicolumn{4}{|c|}{ Dry Weight } & \multirow{2}{*}{\multicolumn{2}{|c|}{ Injury }} & \multirow{2}{*}{\multicolumn{2}{|c|}{$\begin{array}{l}\text { Number } \\
\text { Flowers }\end{array}$}} \\
\hline & & & & & \multicolumn{2}{|c|}{ Root } & \multicolumn{2}{|c|}{ Plant } & \multicolumn{2}{|c|}{ Root } & \multirow[b]{2}{*}{0.06} & \multirow[b]{2}{*}{$\mathrm{a}$} & & & & \\
\hline & 11.47 & $a b$ & 12.06 & $\mathrm{a}$ & 1.91 & $\mathrm{a}$ & 1.02 & $\mathrm{ab}$ & 0.19 & $\mathrm{ab}$ & & & 6 & $\mathrm{~h}$ & 2.8 & $\mathrm{ab}$ \\
\hline Medium & 11.03 & abcd & 11.03 & $\mathrm{a}$ & 1.71 & $a b$ & 1.06 & $\mathrm{a}$ & 0.18 & abcd & 0.07 & $\mathrm{a}$ & 7 & $\mathrm{~h}$ & 2.6 & $\mathrm{ab}$ \\
\hline 1 & 9.13 & efg & 9.70 & $\mathrm{a}$ & 1.63 & $\mathrm{ab}$ & 1.00 & $\mathrm{ab}$ & 0.17 & abcd & 0.04 & $\mathrm{a}$ & 26 & cde & 2.6 & $\mathrm{ab}$ \\
\hline 2 & 8.87 & fg & 11.93 & $\mathrm{a}$ & 1.62 & $\mathrm{ab}$ & 1.04 & $\mathrm{a}$ & 0.18 & $a b c$ & 0.06 & $\mathrm{a}$ & 31 & bcd & 2.5 & $\mathrm{ab}$ \\
\hline 3 & 9.33 & defg & 9.53 & $\mathrm{a}$ & 1.80 & $\mathrm{a}$ & 0.97 & $\mathrm{ab}$ & 0.18 & $a b c$ & 0.04 & $\mathrm{a}$ & 12 & gh & 2.6 & $\mathrm{ab}$ \\
\hline 4 & 9.37 & bcdef & 11.00 & $\mathrm{a}$ & 1.63 & $a b$ & 0.95 & $\mathrm{ab}$ & 0.16 & bcd & 0.04 & $\mathrm{a}$ & 15 & fgh & 3.7 & $\mathrm{a}$ \\
\hline 5 & 10.23 & bcdef & 9.63 & $\mathrm{a}$ & 1.86 & $\mathrm{a}$ & 1.02 & $\mathrm{ab}$ & 0.20 & $\mathrm{a}$ & 0.05 & $\mathrm{a}$ & 25 & def & 2.5 & $\mathrm{ab}$ \\
\hline 6 & 9.50 & bcdef & 9.60 & $\mathrm{a}$ & 1.45 & $\mathrm{~b}$ & 0.96 & $\mathrm{ab}$ & 0.14 & $\mathrm{~d}$ & 0.05 & $\mathrm{a}$ & 40 & $a b$ & 2.3 & $\mathrm{~b}$ \\
\hline 7 & 9.73 & g & 9.59 & $\mathrm{a}$ & 1.69 & $a b$ & 1.04 & $\mathrm{a}$ & 0.15 & $\mathrm{~cd}$ & 0.04 & $\mathrm{a}$ & 25 & def & 2.6 & $\mathrm{ab}$ \\
\hline 8 & 10.10 & $a b c$ & 11.87 & $\mathrm{a}$ & 1.78 & $\mathrm{a}$ & 0.99 & $\mathrm{ab}$ & 0.20 & $\mathrm{a}$ & 0.06 & $\mathrm{a}$ & 36 & $a b c$ & 3.2 & $\mathrm{ab}$ \\
\hline 9 & 8.27 & def & 12.20 & $\mathrm{a}$ & 1.78 & $\mathrm{a}$ & 1.01 & $a b$ & 0.19 & $a b c$ & 0.06 & $\mathrm{a}$ & 15 & fgh & 2.9 & $\mathrm{ab}$ \\
\hline 10 & 11.17 & $a b$ & 11.90 & $\mathrm{a}$ & 1.72 & $\mathrm{ab}$ & 0.91 & $a b$ & 0.19 & $\mathrm{ab}$ & 0.05 & $\mathrm{a}$ & 31 & abcd & 2.5 & $\mathrm{ab}$ \\
\hline 11 & 10.53 & $a b c$ & 10.43 & $\mathrm{a}$ & 1.61 & $\mathrm{ab}$ & 0.88 & $a b$ & 0.15 & bcd & 0.04 & $\mathrm{a}$ & 18 & efg & 2.1 & $\mathrm{~b}$ \\
\hline 12 & 11.73 & abcdef & 10.93 & $\mathrm{a}$ & 1.69 & $a b$ & 0.82 & $\mathrm{~b}$ & 0.19 & $a b c$ & 0.05 & $\mathrm{a}$ & 38 & $a b$ & 2.4 & $\mathrm{ab}$ \\
\hline 13 & 11.13 & $a b c$ & 11.77 & $\mathrm{a}$ & 1.71 & $\mathrm{ab}$ & 0.92 & $a b$ & 0.20 & $\mathrm{a}$ & 0.05 & $\mathrm{a}$ & 13 & gh & 2.4 & $\mathrm{ab}$ \\
\hline 14 & 11.97 & $\mathrm{a}$ & 11.63 & $\mathrm{a}$ & 1.78 & $\mathrm{a}$ & 0.95 & $a b$ & 0.19 & $a b$ & 0.06 & $\mathrm{a}$ & 36 & $a b c$ & 2.3 & $\mathrm{~b}$ \\
\hline 15 & 10.60 & abcde & 11.40 & $\mathrm{a}$ & 1.85 & $\mathrm{a}$ & 0.99 & $a b$ & 0.20 & $\mathrm{a}$ & 0.06 & $\mathrm{a}$ & 39 & $\mathrm{ab}$ & 2.8 & $\mathrm{ab}$ \\
\hline 16 & 11.20 & $a b c$ & 10.83 & $\mathrm{a}$ & 1.86 & $\mathrm{a}$ & 0.96 & $a b$ & 0.20 & $\mathrm{a}$ & 0.05 & $\mathrm{a}$ & 41 & $\mathrm{a}$ & 3.0 & $\mathrm{ab}$ \\
\hline 17 & 10.83 & abcdef & 10.77 & $\mathrm{a}$ & 1.88 & $\mathrm{a}$ & 0.91 & $a b$ & 0.18 & $a b c$ & 0.06 & $\mathrm{a}$ & 41 & $a b$ & 2.6 & $\mathrm{ab}$ \\
\hline Average & 10.33 & & 10.94 & & 1.73 & & 0.97 & & 0.18 & & 0.05 & & 26.12 & & 2.65 & \\
\hline C.V. (\%) & 12.81 & & 19.98 & & 14.38 & & 16.58 & & 16.35 & & 44.73 & & 31.4 & & 40.5 & \\
\hline
\end{tabular}

* Means followed by the same letter in the column do not show a statistical difference, by the Shapiro-Wilk test at 5\% probability.

From the data of Tables 2 and 3 it is seen that the bioherbicide has activity towards the target plant and that the degree of injury was influenced by the independent variables studied here. However, the influence of each variable on the response is not completely determined in the results discussed above. For this reason, the data of Table 2 were used to compute the magnitude and significance of these effects, which are presented in Table 4. The CSL did not present a significant influence on herbicidal activity; on the other hand, the effects of moisture and soybean bran were statistically significant $(\mathrm{p}<0.1)$ indicating a positive influence on the response with the increase of concentration of both variables. Quadratic terms for soybean bran and moisture content were statistically significant and both were negative, indicating the presence of a maximum point for these variables in the evaluated range. Interaction terms were not significant in the evaluated range.

The results presented in Table 4 were used to build a quadratic model expressing the herbicidal activity as a function of the independent variables. Eq. 1 presents the significant terms of the model $(\mathrm{p}<0.1)$.

$$
F B_{S}=39.86+4.46 \cdot M-5.57 \cdot M^{2}+5.91 \cdot S-5.04 \times S^{2}-3.80 \cdot C^{2}
$$


where $\mathrm{FB}_{\mathrm{s}}$ is the phytotocixity of the bioherbicide, $\mathrm{M}, \mathrm{S}$ and $\mathrm{C}$ are the coded moisture, soybean bran and corn steep liquor contents, respectively. The model was validated by analysis of variance (ANOVA). The calculated F-test for Eq. 1 was about 13 times greater than the tabulated one $(\mathrm{p}=0.1)$ and the determination coefficient $(\mathrm{R})$ was 0.8439 . The high value for the determination coefficient indicated good fitting of the experimental data, allowing the use of the model to predict the bioherbicidal activity towards plant targets.

The validated model was used to determine the optimum conditions for bioherbicide production and the results obtained are presented in Figs. 1, 2 and 3, which show the influence of moisture and CSL content, moisture and soybean bran contents and CSL and soybean bran contents on the phytotoxicity of the bioherbicide, respectively. Analyzing these Figures together it is possible to delimit the optimum point for bioherbicide production that was a moisture content of $70 \%$, soybean bran of $30 \%$ and CSL of $20 \mathrm{wt} \%$. Under this condition, the maximum bioherbicide action on the target plant was around 40 on the scale used.

Table 4. Analysis of the effects of independent variables of the CCRD on the bioherbicide production.

\begin{tabular}{lcccc}
\hline & Effect & Std. Err. & t(10) & p-value \\
\hline Mean & 39.87 & 4.07 & 9.80 & $<0.0001$ \\
\hline Moisture (L) & 8.92 & 3.82 & 2.33 & 0.0418 \\
\hline Moisture (Q) & -11.15 & 4.21 & -2.65 & 0.0245 \\
\hline CSL (L) & -0.06 & 3.82 & -0.02 & 0.9881 \\
\hline CSL (Q) & -7.60 & 4.21 & -1.81 & 0.1012 \\
\hline Soybean (L) & 11.82 & 3.82 & 3.09 & 0.0114 \\
\hline Soybean (Q) & -10.08 & 4.21 & -2.39 & 0.0377 \\
\hline Moisture x CSL & -1.50 & 5.14 & -0.29 & 0.7787 \\
\hline Moisture x Soybean & 4.50 & 5.14 & 0.88 & 0.4099 \\
\hline CSL x Soybean & 6.50 & 5.14 & 1.27 & 0.2461 \\
\hline
\end{tabular}

L: linear term; Q: quadratic term and CSL: corn steep liquor

The action of a bioherbicide on the plant depends on absorption, translocation, metabolism and the plant sensitivity to the active compound. It is necessary for the compound to penetrate into the plant, translocate and reach the organelle where it will act. The same herbicide may influence various metabolic processes in the plant; however, the first biophysical or biochemical injury that it causes in the plant is characterized by its mechanism of action. The sequence of all reactions to the final action of the product on the plant constitutes its mode of action. The knowledge of the mechanism of action and mode of action is an important step in the development of a bioherbicide. From analysis of bioassays some common symptoms among the treatments were observed, which allowed grouping of the possible mechanism of action of bioherbicide produced from Phoma sp.

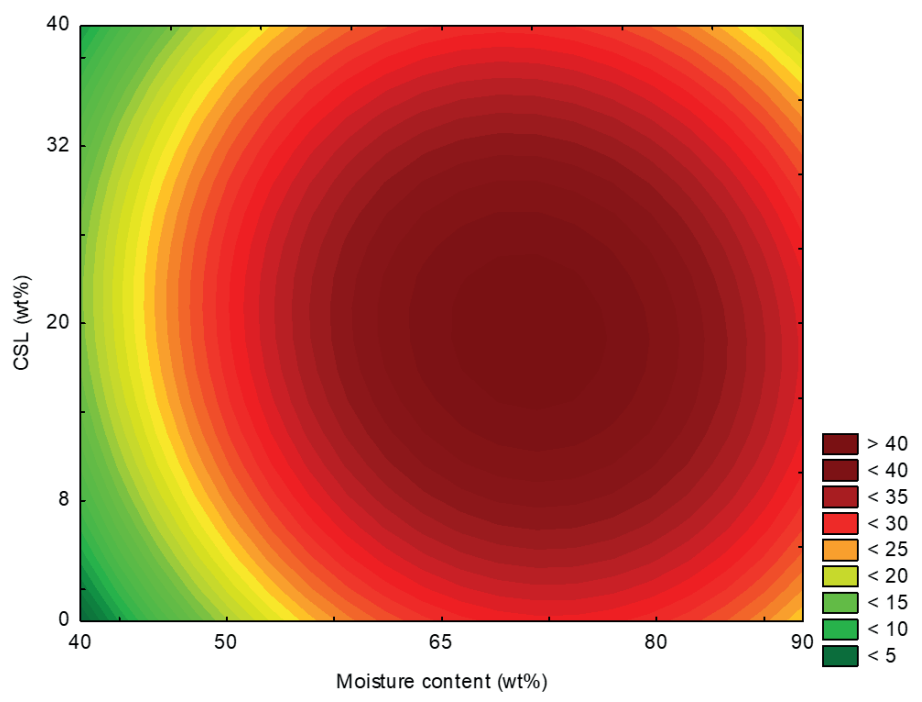

Figure 1. Contour plots showing the influence of moisture and CSL (corn steep liquor) contents on the phytotoxicity of the bioherbicide produced. Soybean bran content was maintained at the central point of the CCRD. 


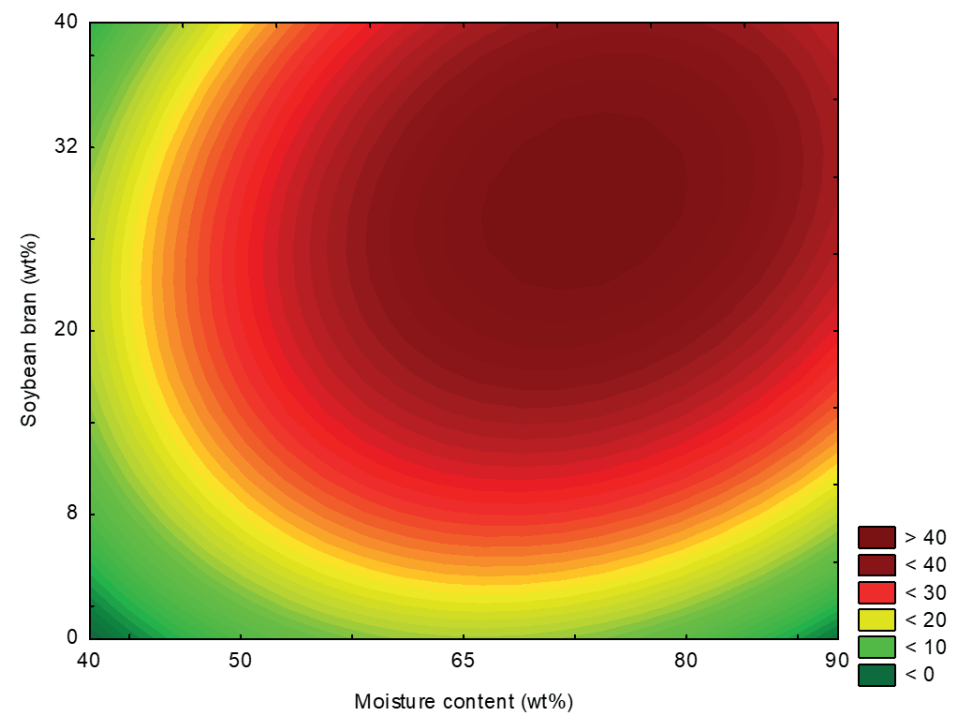

Figure 2. Contour plots showing the influence of moisture and soybean bran contents on the phytotoxicity of the bioherbicide produced. CSL (corn steep liquor) content was maintained at the central point of the CCRD.

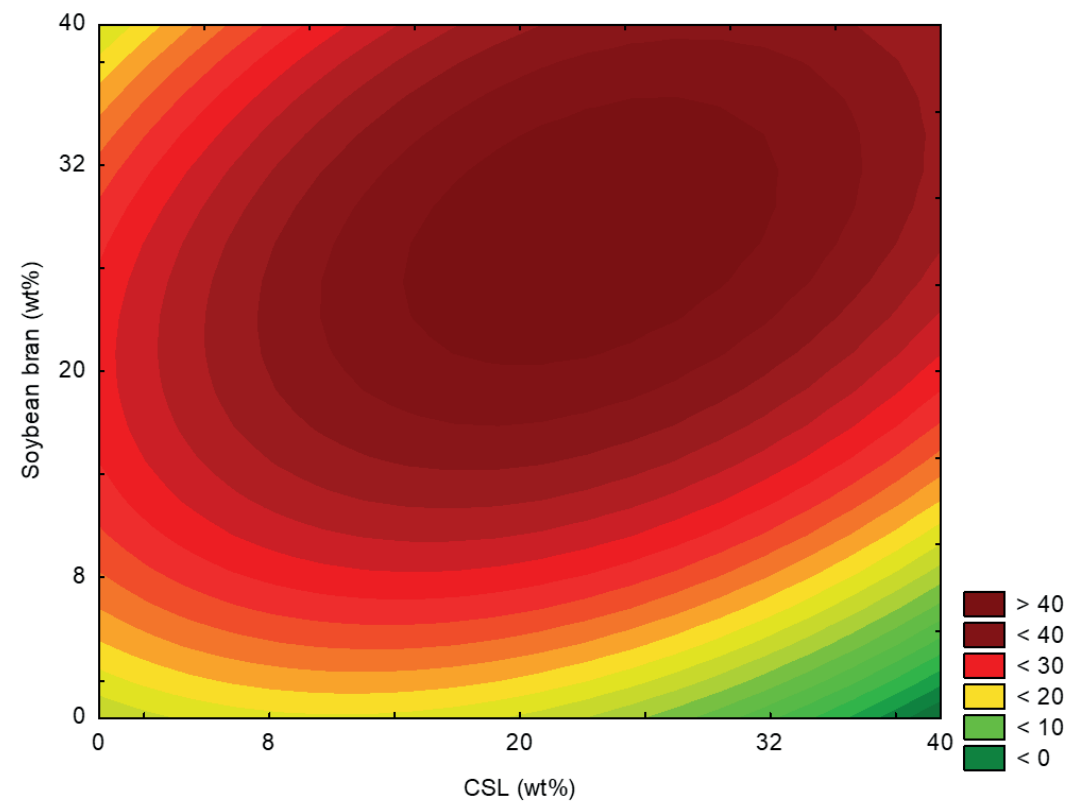

Figure 3. Contour plots showing the influence of CSL (corn steep liquor) and soybean bran contents on the phytotoxicity of the bioherbicide produced. Moisture content was maintained at the central point of the CCRD.

The main symptom observed in the experiments was the bleaching of the leaves that came into contact with the bioherbicide. The leaves that were born after the application did not show the symptom. Fig. 4 shows the injury caused by the bioherbicide in the experiments of the CCRD with the highest level. These symptoms are similar to herbicides that have a mechanism of action based on the inhibition of carotenoid biosynthesis. This mechanism of action is mainly characterized by depigmentation of the leaves caused by photobleaching of chlorophyll that occurs after blockage of the synthesis of carotenoid pigments (Duke and Dayan, 2011; Copping and Duke, 2007). 


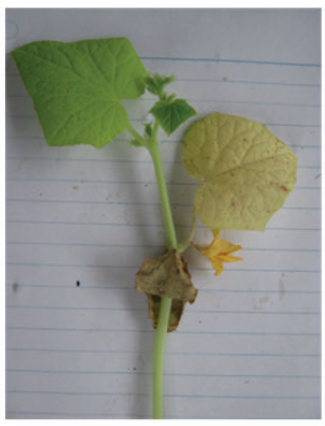

a)

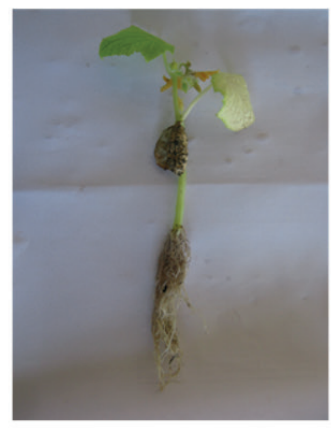

b)

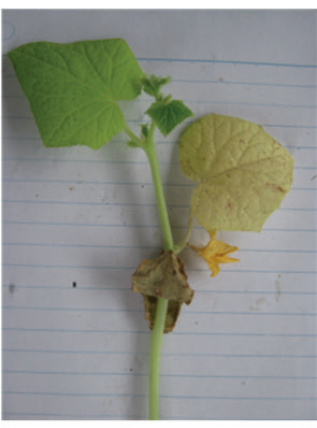

c)

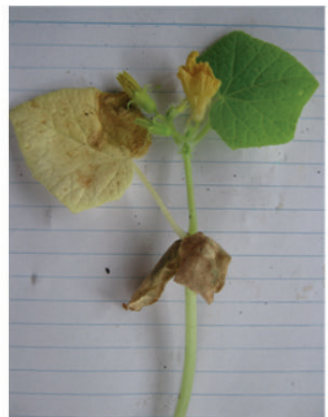

d)

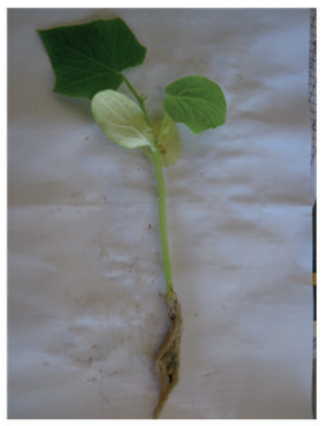

e)

Figure 4. Effect of bioherbicide on the target plant for some specific runs of the CCRD: a) run 6 ; b) run 8 ; c) run 12 ; d) run 15 ; e) control.

\section{CONCLUSIONS}

In this work solid-state fermentation for bioherbicide production from Phoma sp was optimized. Results of the bioassays demonstrate that the bioherbicide presented activity towards the target plant and that the intensity of the effect was influenced by the formulation of the fermentation medium. The most severe injury was seen in treatment 6 , with significant reduction of the height as well as fresh and dry weight of the aerial parts. The optimized condition for bioherbicide production was at a moisture content of 70 $\mathrm{wt} \%$, soybean bran content of $30 \mathrm{wt} \%$ and CSL content of $20 \mathrm{wt} \%$, it being possible to obtain an injury level of 40 . The bioherbicide produced showed a mode of action based on the inhibition of carotenoid biosynthesis.

\section{ACKNOWLEDGEMENTS}

The authors thank CAPES for the scholarships and FAPERGS for the financial support of this work.

\section{REFERENCES}

Ash, G.J., The science art business of successful bioherbicides. Biological Control 52, 230-240 (2010).

Bailey, K.L., Pitt, W.M., Falk, S., Derby, J., The effects of Phoma macrostoma on nontarget plant and target weed species. Biological Control, 58, 379-386 (2011).

Barton, J., How good are we at predicting the field hostrange of fungal pathogens used for classical biological control of weeds? Biological Control, 31, 99-112 (2004).

Boyetchoko, S.M., Rosskopf, E.N., Caesar, A.J., Charudattan, R., Biological weed control with pathogens: Search for candidates to applications. Agriculture and Food Production, 2, 239-266 (2002).

Charudattan, R., Dinoor, A., Biological control of weeds using plant pathogens: accomplishments and limitations. Crop Protection, 19, 691-695 (2000).

Copping, L.G., Duke, S.O., Natural products that have been used commercially as crop protection agents. Pest Management Science, 63(6), 524-554 (2007).

Duke, S.O., Dayan, F.E., Modes of Action of MicrobiallyProduced Phytotoxins. Toxins 3, 1038-1064 (2011).

Frans, R., Crowley, H., Experimental design and techniques for measuring and analyzing plant responses to weed control practices. In: Southern Weed Science Society. Research methods in weed science, Clemson, $3^{\mathrm{a}}$ ed., 29-45 (1986).

Green, J.M., Current state of herbicides in herbicideresistant crops. Pest Management Science, 70, 13511357 (2014).

Hoagland, R.E., Boyette, C.D. Weaver, M.A., Bioherbicides: Research and risks. Toxin Reviews 26, 313-342 (2007).

Klaic, R., Kuhn, R.C., Foletto, E.L., Dal Prá, V., Jacques, R.J.S., Guedes, J.V.C., Treichel, H., Mossi, A.J., Oliveira, D., Oliveira, J.V., Jahn, S.L., Mazutti, M.A., An overview regarding bioherbicide and their production methods by fermentation. In: Vijai Kumar Gupta; Robert L. Mach; S. Sreenivasaprasad. (Org.). Fungal Bio-Molecules: Sources, Applications and Recent Developments. 1ed.Oxford: Wiley-Blackwell, 2015, v. 1, p. 183-200 (2015).

Klaic, R., Sallet, D., Souza, A.R.C., Guedes, J.V.C., Jacques, R.J.S., Foletto, E.L., Jahn, S.L., Kuhn, R.C., Mazutti, M.A., Biopesticide Patents. Recent Patents in Engineering. 7, 182-195 (2013).

Mitchell, K.J., Development of a submerged-liquid sporulation medium for the potential smartweed bioherbicide Septoria polygonorum. Biological Control, 27, 293-299 (2003).

Pandey, A., Solid-state fermentation. Biochemical Engineering Journal, 13, 81-84, 2003. 
Parra, R., Aldred, D., Magan, N., Medium optimization for the production of the secondary metabolite squalestatin S1 by a Phoma sp. combining orthogonal design and response surface methodology. Enzyme and Microbial Technology, 37, 704-711 (2005).

Penariol, M.C., Monteiro, A.C., Pitelli, R.A., 2008. Growth and sporulation of Bipolaris euphorbiae cultivated under different nutritional conditions. Ciência Rural 38, 1907-1913.

Rosskopf, E.N., Charudattan, R., Kadir, J.B., Use of plant pathogens in weed control. Handbook of Biological Control (1999).
Singhania, R.R., Sukumaran, R.K., Patel, A.K., Larroche, C., Pandey, A., Advancement and comparative profiles in the production technologies using solid-state and submerged fermentation for microbial cellulases. Enzyme and Microbial Technology, 46, 541-549 (2010).

Zhang, L., Wang, S.Q., Li, X.J., Zhang, A.L., Zhang, Q., Gao, J.M., New insight into the stereochemistry of botryosphaeridione from a Phoma endophyte. Journal of Molecular Structure, 1016, 72-75 (2012).

Zhou, L., Bailey, K.L., Derby, J., Plant colonization and environmental fate of the biocontrol fungus Phoma macrostoma. Biological Control 30, 634-644 (2004). 